\title{
Adsorption-desorption and kinetics studies of Methylene Blue Dye on Na-bentonite from Aqueous Solution
}

\author{
M. El Miz ${ }^{1}$, H. Akichouh ${ }^{1}$, S. Salhi ${ }^{1}$, A. El Bachiri ${ }^{1}$, And A. Tahani ${ }^{1}$ \\ ${ }^{I}:$ ( LACPRENE, Bloc de recherche ème étage, / Faculté des Sciences Oujda, / université Mohamed ler; Route \\ de Sidi Maâfa ; BP 524-Oujda-Morocco)
}

\begin{abstract}
Bentonite, which is composed mainly of clay minerals belonging to the smectite group, has a great scope in chemistry and industry. This study was conducted with a sample collected from the region of Nador (northeastern Morocco, North Africa), which is changed and purified sodium. In this work, adsorption experiments were carried out for the blue using the homo- ion exchanged sodium bentonite. The adsorption isotherms are determined experimentally and analyzed by different models( Langmuir, Freundlich and Redlich Peterson).

The experimental data were analyzed by the Freundlich and the Langmuir isotherm types for low values of equilibrium concentration. The rise of the isotherm in this range of concentrations was related to the affinity of Methylene Blue for clay sites, and the equilibrium data fitted well with the Freundlich model with maximum adsorption capacity of $309,677 \mathrm{mg} / \mathrm{g}$ for a ratio $R S / L=0.13 \%$. Pseudo-first and pseudo-second-order kinetic models were tested with the experimental data and pseudo-second order kinetics was the best for the adsorption of Methylene Bleu with coefficients of correlation $R^{2} \geq 1$, and the adsorption was rapid with $96 \%$ of the Methylene Blue adsorbed within the first $18 \mathrm{~min}$.
\end{abstract}

Key Words: Clays - Bentonite -Methylene Blue - Adsorption-Desorption- kinetics- Na-bentonite Clay

\section{Introduction}

Dyes are widely used in industries such as textiles, leather, printing, food, plastics, etc.

The removal of dyes from industrial wastewaters is a major problem. Conventional methods for the removal of dyes from waste water include adsorption onto solid substrates, chemical coagulation, oxidation, filtration and biological treatment. [1]. Several methods to treat industrial effluents have been developed for decontamination purposes including coagulation, chemical oxidation, membrane separation, electro-chemical process, and adsorption techniques.

Adsorption was recognized to be a promising and a cost effective process to remove dye stuffs from aqueous solution. Many kinds of adsorbents have been developed for various applications. Due to its effectiveness and versatility, activated carbon is widely employed in water and wastewater treatment [2].

The operating cost of activated carbon adsorption is still high. Problems of regeneration and difficulty in separation from the wastewater after use are the two major concerns of using this material [3].

The absorption of methylene blue dye by clay minerals is currently used for determining either their cation exchange capacities [4-6] or their surface areas [7-9]. However, the usefulness of the method is often questioned $[10 ; 11]$, and confusions have arisen when it comes to understanding which of these properties is being primarily measured. In some cases, it appears that when the clay surface is more or less covered by methylene blue ions, a more or less complete exchange of the initial cations by the dye also takes place, which explains the difficulty of knowing which property primarily is measured.

Adsorption is one of the effective separation technique to remove dilute pollutants as well as offering the potential for regeneration, recovery and recycling of the adsorbend material [12].

The application of clays known a considerable development in many industrial sectors such as: oil industry, oil purification ..... and this study aims to extend the use of local clays to new fields of application and particular fading in them, the food encapsulation of essential oils in cosmetic.

To do this we conducted physico-chemical studies and studies of the mechanisms of adsorption and desorption kinetics of Methylene Bleu on Na-bentonite (smectite clay).

\section{II-1. Adsorbent and adsorbat}

\section{Materials And Methods}

Natural clay from North-East of Morocco (Nador), was used in a purified form. The clay is an industrial bentonite rich with montmorillonite clay type. A cationic dye, methylene blue, having molecular formula $\mathrm{C}_{16} \mathrm{H}_{18} \mathrm{~N}_{3} \mathrm{SCl}$ was chosen as adsorbate. Methylene blue (Basic Blue 9) was purchased from Merck with Water solubility as $50 \mathrm{~g} \mathrm{~L}^{-1}\left(20^{\circ} \mathrm{C}\right)$ and molecular weight as $319.85 \mathrm{~g} / \mathrm{mol}$. The MB was chosen in this study 
because of its known strong adsorption onto solids. The dye stock solution was prepared by dissolving accurately weighted methylene blue in distilled water to the concentration of $500 \mathrm{mg} \mathrm{L}^{-1}$.

The experimental solutions were obtained by diluting the dye stock solution in accurate proportions to required initial concentrations.

\section{II-2. Purification and preparation of sodium Bentonite}

In this method a mass of $1 \mathrm{Kg}$ of raw clay is dispersed in 5 liters of distilled water with a solid/liquid ratio: 1:5. The mixture was stirred for an hour, until the homogenization full suspension, followed by treatment by $\mathrm{HCl}(0.5 \mathrm{M})$ to remove carbonate. The resulting mixture was washed by $\mathrm{H}_{2} \mathrm{O}_{2}(10 \%)$ to oxidize organic matter.

The resulting product was then washed extensively (6 times) with $\mathrm{NaCl} 1 \mathrm{M}$ and centrifuged to give saturated clays. The dark grey residue in the centrifuge tube was eliminated because it contained the fraction enriched in impurity (quartz, cristobalite, feldspar ...)

The samples were then washed and dialyzed against distilled water until the conductivity in the dialysis bath was less than $2 \mu \mathrm{S} / \mathrm{cm}$. The granular fraction size $\leq 2 \mu \mathrm{m}$ were then obtained by accurate sedimentation. The air-dried clays were gently grounded to give a powder [13].

\section{II-3. Characterization}

The natural samples purified and modified clay are subjected to analysis and identification by X-ray diffraction (XRD), infrared spectroscopy (IR) and Thermal analysis.

X-ray diffractograms were recorded in a Shimadzu XRD diffractometer D6000 stations working on the monochromatic copper Ka1 radiation (1.54 §). (Figures 2).

Infra Red (I.R) spectra were acquired using a Shimadzu Fourier Transform spectrometer over a range varying from 400 to $4000 \mathrm{~cm}^{-1}$ with a resolution of $2 \mathrm{~cm}^{-1}$, and the samples were prepared in the form of a dispersion in a vial $\mathrm{KBr}(1 / 200$ by weight) (Figures 3$)$.

Thermal analysis was carried out in a SHIMATZU D6000 coupled to a DC ampler and temperature controller. Data from DTA-TG were obtained in all cases at a heating rate of $5^{\circ} \mathrm{C} / \mathrm{min}$ between 30 and $1000^{\circ} \mathrm{C}$ and under $\mathrm{N}_{2}$ atmosphere (Figures 4).

\section{II-4. Adsorption studies}

It is widely accepted that the process of adsorption can be represented by four consecutive steps [14]. (Figure 1) describes the progression of a molecule of adsorbate from the bulk towards the site of adsorption.

It is important to note that intra-particle mass transfer involves two different phenomena: porous diffusion (the adsorbate first diffuses in the liquid filling the pores and then is adsorbed) and surface diffusion (the adsorbate is first adsorbed then diffuses from one site to another).

The convective progression of step 1 appears to be very fast compared to the diffusion through the outer layer and within the particle. The concentrations of the liquid bulk will only be governed by the overall mass balance and the hydraulic behaviour of the vessel.

An instantaneous reversible reaction is assumed for the real adsorption step (step 4). The liquid phase concentration of adsorbate and the adsorbate load at the car-bon's surface are locally related by an equilibrium law.

Thus adsorption kinetic is governed by external mass transfer and internal diffusion i.e. by the coefficients $\mathrm{K}_{\mathrm{F}}, \mathrm{D}_{\mathrm{P}}$ and $\mathrm{D}_{\mathrm{S}}$. In order to simplify simulations, models that take into account only two coefficients were developed. As noticed by [15] the contribution of $D_{S}$ is 20 times as important as the $D_{P}$ contribution. Later, in a review paper, [16] mentioned several other authors confirming this observation [17]. Therefore a model based only on $\mathrm{K}_{\mathrm{F}}$ and $\mathrm{D}_{\mathrm{S}}$ will be used here.

In this study we Preparat a series of different product concentration Co $(20 \mathrm{ml})$, and $0.5 \%$ to the suspension of clay is added 0.5 grams of clay in $100 \mathrm{ml}$ of distilled water and then adding $5 \mathrm{ml}$ of suspension to $20 \mathrm{ml}$ our Co solution, and placed under stirring for $24 \mathrm{~h}$ (balance) at a temperature of $19^{\circ} \mathrm{C}$. then centrifugation at a speed of $10000 \mathrm{rev} / \mathrm{min}$ for 20 minutes, the equilibrium concentration of Methylene Blue was measured by UV. The amount adsorbed on clay was calculated from the initial concentration and final concentration of the products determined by UV-visible spectroscopy.

The desorption experiments were carried out after an adsorption step in the same conditions as described above. After adsorption and phase separation by centrifugation, the supernatant solutions were discarded. Volume of solution remaining in the pellets was calculated by weight and the amount of non adsorbed Methylene Blue was calculated. Account was taken of the Methylene Blue remaining in the solution of the moist clay pellet in calculations of the fraction desorbed. The adsorption capacity of Methylene Blue molecules adsorbed per gram adsorbent $(\mathrm{mg} / \mathrm{g})$ was calculated using the equation:

$$
q_{e}=\frac{V}{m} \times\left(C_{0}-C_{e}\right) \quad \text { eq1 }
$$


With: $\mathrm{C}_{0}$ is the initial concentration $(\mathrm{mg} / \mathrm{L}), \mathrm{Ce}$ is the equilibrium concentration, $\mathrm{V}(\mathrm{ml})$ is the total volume of the sample, $\mathrm{m}(\mathrm{mg})$ is the mass of clay used and qe is the amount adsorbed $\mathrm{mg}$ per grams of clay $(\mathrm{mg} / \mathrm{g})$. The product under consideration adsorption isotherm is obtained by drawing the curve:

$$
\mathrm{qe}=f\left(\mathrm{C}_{\mathrm{e}}\right)
$$

For the adsorption experience, the mass of Methelene Blue that was lost during the balancing of the solution was supposed to be adsorbed by the clay. The dye percent removal (\%) was calculated using the following equation:

$$
\operatorname{Removal}(\%)=\frac{(C o-C e)}{C o} \times 100 \quad \text { eq2 }
$$

The sequential (adsorption / desorption) run were conducted to determine the mobilization factor [18] following the equation:

$$
K_{\mathrm{s} D}=\frac{M_{a d s}}{M_{\text {des }}} \quad \text { eq3 }
$$

Where: KSD : the adsorption : desorption ratio; Mads: the amount of solute adsorbed (mg/g); Mdes: the amount of solute desorbed $(\mathrm{mg} / \mathrm{g})$.

\section{II-5. Adsorption kinetic}

The adsorption kinetics shows the evolution of the adsorption capacity through time and it is necessary to identify the types of adsorption mechanism in a given system.

The dynamics of sorption describes the rate of MB uptake on Na-Bentonite and this rate controls the equilibrium time [19]. Information on the dynamics of sorption is required for selecting optimum operating conditions for the full scale batch process [20].

For kinetic studies, solutions of $3.66,4,5,8,10$ and $20 \mathrm{mg} \mathrm{L}-1$ methylene blue, as the initial concentration each, were treated with $17.566 \mathrm{mg} \mathrm{L}-1$ of Na-bentonite at a constant temperature of $292{ }^{\circ} \mathrm{K}$. The mixtures were then subjected to agitation at $500 \mathrm{rpm}$. In all cases, the working $\mathrm{pH}$ was that of solution 5.33 Mixtures were taken from the shaker at appropriate time intervals $(1,5,10,15,20,30,45,60,90,180 \mathrm{~min})$ and the left out concentration in the methylene blue solution was estimated as have been explained before.

$$
q_{t}=\frac{V \times\left(C_{0}-C_{t}\right)}{m}
$$

Where $\mathrm{Ct}(\mathrm{mg} / \mathrm{L})$ is concentrations of Methylene Blue at time $\mathrm{t}(\mathrm{min})$.

\section{III-1. Characterization of the bentonite}

\section{Results and discussion}

\section{- Chemical analysis:}

The major element composition of the investigated clay mineral is presented in Table 2 as $\%$ oxides. The main components are $\mathrm{SiO}_{2}(61.17 \%)$ and $\mathrm{Al}_{2} \mathrm{O}_{3}(15.13 \%)$, with the exception of hectorite, which contains $\sim 6 \% \mathrm{MgO}$, $4 \% \mathrm{CaO}, \mathrm{Fe}_{2} \mathrm{O}_{3}(3.25 \%)$ and other elements present in minor amounts $\left(\mathrm{K}_{2} \mathrm{O}, \mathrm{SO}_{3}, \mathrm{CuO}, \mathrm{TiO}_{2}, \mathrm{ZnO}\right)$. A small percentage of organic matter $(\mathrm{MO}=1.08 \%)$ and a percentage of water estimated to $\sim 10.56 \%$.

The surface areas and the pore volumes of the samples were determined by Micrometrics ASAP 2000 volumetric adsorption-desorption apparatus, using nitrogen as adsorbent [21] with: Specific surface $\mathrm{S}_{\mathrm{BET}}=83,5$ $\mathrm{m}^{2} \mathrm{~g}^{-1}$, total pore volume $\mathrm{Vt}=0,213 \mathrm{~cm}^{3} \mathrm{~g}^{-1}$, External specific surface $\mathrm{S}_{\mathrm{ext}}=81,024 \mathrm{~m}^{2} \mathrm{~g}^{-1}$. Its cation exchange capacity, determined by adsorption of a copper ethylene di-amine complex [22; 23] is $107 \mathrm{meq} / 100 \mathrm{~g}$ (ignited) clay. Chemical analyses of the samples are given in Table.1.

The samples of clays were characterized by XRD (X ray diffraction), DTA-TGA (Differential thermal analysis and thermo gravimetric analysis) and (I.R) infrared.

The X-ray diffraction (XRD) of the powder of the purified bentonite showed that the latter is of the same family of smectites with reflection (001) located at $12 \AA$. The presence of the line (06.33) at $\mathrm{d}=1.49 \AA$ showed that it consists of montmorillonite. The presence of crystalline phases in the form of impurities Quartz (Q) $\mathrm{d}=3.34 \AA$ was also noted.

\section{- X-ray diffraction}

The X-ray diffraction (XRD) of the Brute and purified bentonite powder shows that bentonite is of the same smectite family with reflection (001) at 14a. This shows that natural bentonite is a calcium form. The presence of the line (06.33) at $\mathrm{d}=1.49 \AA$ shows that it consists of montmorillonite. It is also noted that there is a presence of crystalline phases in the form of impurities Quartz (Q) $d=3.34 \AA$. 


\section{- FTIR spectroscopy}

FTIR spectra of B-Na purified and raw bentonite clays are given in Figures 3. Examination of the infrared absorption spectra of the crude and purified samples of bentonite shows absorption bands that are presented as follows [24].

The spectra show two absorption bands between 3200 and $3800 \mathrm{~cm}^{-1}$ and between 1600 and $1700 \mathrm{~cm}^{-1}$. The tape that lies between 1600 and $1700 \mathrm{~cm}-1$ is attributed to stretching vibrations of the $\mathrm{OH}$ group constitution water plus the vibration binding adsorbed water. The band in the range 3200-3800 cm-1 with a strong peak at the shoulders 3435 and $3621 \mathrm{~cm}-1$ characterize the montmorillonite and correspond to stretching vibrations of the $\mathrm{OH}$ groups of the octahedral layer is coordinated with $\mathrm{Al}^{3+} \mathrm{Mg}^{2+}\left(3640 \mathrm{~cm}^{-1}\right)$ or $\mathrm{Al} 2\left(3600 \mathrm{~cm}^{-}\right.$ $\left.{ }^{1}\right)$.

The deformation vibrations of $\mathrm{H}_{2} \mathrm{O}$ molecules are characterized by the band $3400 \mathrm{~cm}^{-1}$. The band, centered around $1630 \mathrm{~cm}^{-1}$, is assigned to the deformation vibrations of $\mathrm{H}_{2} \mathrm{O}$ molecules adsorbed between the sheets.

The intense band situated between 900 and $1200 \mathrm{~cm}^{-1}$ and centered around $1040 \mathrm{~cm}^{-1}$ corresponds to stretching vibrations of Si-O bond . In the purified clay (Na-montm), it is situated around $1030 \mathrm{~cm}^{-1}$ between 1115 and $1020 \mathrm{~cm}^{-1}$. The bands situated at 425,525 and $468 \mathrm{~cm}^{-1}$ are assigned respectively to the deformation vibration of Si- O- Al bonds, Si- $\mathrm{O}$ and $\mathrm{Si}-\mathrm{Mg}-\mathrm{Fe}-\mathrm{O}$.

\section{- Thermal analysis (DTA-TG)}

Examination of the thermal analysis curve of the purified sodium bentonite in (Figures. 4), show, in the field of low temperatures, the existence of a $137^{\circ} \mathrm{C}$ intense endothermic phenomenon, this phenomenon is linked to the starting zeolite and the hygroscopic water of bentonites. Mass loss that accompanied these thermal accidents is very important, it is about $13.54 \%$ of the initial mass. Another endothermic phenomenon of low intensity occurs at a temperature of $640^{\circ} \mathrm{C}$. It corresponds to the departure of the structural water. The mass loss associated with this phenomenon is about $3.62 \%$ of weight. The DTA curve also exhibits an exothermic accident to $894.25^{\circ} \mathrm{C}$ due to the crystallization of the bentonite.

The DTA curve relating to the Brute bentonite presents two endothermic phenomena at $100{ }^{\circ} \mathrm{C}$ and 240 ${ }^{\circ} \mathrm{C}$. This duplication is due to the presence of two types of water molecules, these are respectively Hygroscopic and Zeolitic water. Two other endothermic phenomena of low intensity occur in the area of average temperature $580{ }^{\circ} \mathrm{C}$ and $680^{\circ} \mathrm{C}$ correspond respectively to the strongly retained water and water of constitution. The DTA curve also shows a broad exothermic accident in the temperature range of $820^{\circ} \mathrm{C}$ and $930{ }^{\circ} \mathrm{C}$.

\section{III-2. Data processing}

The adsorption isotherm indicates how the adsorption molecules distribute between the liquid phase and the solid phase when the adsorption process reaches an equilibrium state.

The analysis of the isotherm data by fitting them to different isotherm models is an important step to find the suitable model that can be used for design purpose. There are several isotherme quations available for analyzing experimental adsorption equilibrium data.

In this study, the equilibrium experimental data for adsorbed MB on Na-bentonite sample were analyzed using the Langmuir and Freundlich models.

\section{III-3. Adsorption isotherms and Equilibrium studies:}

\section{- Adsorption isotherms, Solid/Liquid ratio and concentration effects}

Under ideal saturated conditions, the solid liquid ratio should not influence the amount of organic or inorganic molecules adsorbed per unit of adsorbent. However, some interested studies have shown that both organic and inorganic contaminant adsorption is dependent on solid-liquid ratio to some degree [25].

The (Figure 5) shows the effect of initial concentration and for various solid/liquid ratios on adsorption of Methylene Blue onto Na-bentonite. Along with the increase of adsorbent dosage from $0.5-500 \mathrm{mg} \mathrm{L}^{-1}$, the percentage of dye adsorbed increased to $96.91 \%$ and the decrease of the solid/liquid ratio showing the adsorption process to be dependent on the initial concentration and the content of the solid adsorbent. Above $400 \mathrm{mg} \mathrm{L}-1$ of adsorbent dose, the adsorption equilibria of dye were reached and the removal ratios of dye kept almost invariable.

Initially, the adsorption isotherms of methylene Blue molecules show a rising part whose slope increases when the amount of solid decreases, suggesting a strong affinity of the molecules for the surface sites and translating one monolayer adsorption. The isotherm obtained is L-type by Giles classification [26].

The amount of adsorption reaches a limiting value of around $309.677 \mathrm{mg} \mathrm{g}^{-1}$ for low solid/liquid ratio $(0.13 \%)$. The high adsorption capacity for Methylene Blue uptake presented by Na-bentonite may be caused by adsorption by attractive interactions between the negative charge of Si-O- and the positive charge of Methylene Blue ion $(\mathrm{MB}+)$, (ionic exchange with the Na-bentonite). 
- Effect of contact time and initial concentration on adsorption of MB onto the Na-Bentonite:

The adsorption kinetics study of chemical compound in aqueous solution is generally carried out for small concentration ranges.

The objective of this part is to investigate the apparent adsorption rate at different concentrations, and secondly, try to determine the rate constants and other useful sizing parameters.

The effect of initial concentration on the sorption of $\mathrm{MB}$ on Na-bentonite is presented in (Figure 5) This result was obtained at the initial concentration range of $3-20 \mathrm{mg} / \mathrm{l}$ of $\mathrm{MB}$ at a fixed sorbent dosage $(0.17$ $\mathrm{g} / \mathrm{l}), \mathrm{T}=19^{\circ} \mathrm{C}$, fixed agitation speed $(500 \mathrm{rpm})$ and $\mathrm{pH}=5.64$.

In the range of $\mathrm{MB}$ concentration studied, the uptake of the $\mathrm{MB}$ was rapid in the first $5 \mathrm{~min}$. The rapid uptake then gave way to a much slower adsorption after 18 min (Figure 7).

This initial rapid uptake can be attributed to the concentration gradient created at the start of the adsorption process between solute concentration in solution and that at the Na-bentonite surface.

As the dye loading increases on the sorbent, this gradient reduces and gives way to a slower uptake

\section{III-4. Equilibrium modeling}

The adsorption isotherm indicates how the adsorption molecules distribute between the liquid phase and the solid phase when the adsorption process reaches an equilibrium state.

The analysis of the isotherm data by fitting them to different isotherm models is an important step to find the suitable model that can be used for design purpose. There are several isotherm equations available for analyzing experimental adsorption equilibrium data.

Three isotherms were tested for their ability to describe the experimental results, namely the Langmuir isotherm, the Freundlich isotherm and the Temkin isotherm.

\section{- The Langmuir isotherm model:}

The Langmuir adsorption model [27] is based on the assumption that maximum adsorption corresponds to a saturated monolayer of solute molecules on the adsorbent surface, with no lateral interaction between the sorbed molecules (Figure. 8).

The linear expression of the Langmuir model is given by Eq 5 .

$$
\frac{C_{e}}{q_{e}}=\frac{1}{K_{L} \times q_{m}}+\left(\frac{1}{q_{m}}\right) \times C_{e} \quad \text { eq5 }
$$

The Langmuir constants $\mathrm{qm}$ and $\mathrm{K}_{\mathrm{L}}$ were determined from the slope and intercept of the plot and are presented in Table 2 .

The essential characteristics of the Langmuir isotherm can be expressed in terms of a dimensionless constant separation factor RL that is given by Eq. 6 [28]:

$$
R_{L}=\frac{1}{1+K_{L} \times C_{0}} \quad \text { eq6 }
$$

Where $\mathrm{C}_{0}$ is the highest initial concentration of adsorbate $(\mathrm{mg} / \mathrm{L})$, and $\mathrm{K}_{\mathrm{L}}(\mathrm{L} / \mathrm{mg})$ is Langmuir constant.

The value of $R_{L}$ indicates the shape of the isotherm to be either unfavorable $\left(R_{L}>1\right)$, linear $\left(R_{L}=1\right)$, favorable $\left(0<R_{L}<1\right)$, or irreversible $\left(R_{L}=0\right)$. The $R_{L}$ value is $<1$ indicates that the adsorption model is not conformed.

\section{- The Freundlich isotherm model}

The Freundlich isotherm is an empirical equation employed to describe heterogeneous systems. The linear form of Freundlich equation is expressed:

$$
\ln q_{e}=\ln K_{F}+\left(\frac{1}{n}\right) \times \ln C_{e}
$$

Where $K_{F}$ and $n$ are Freundlich constants with $K_{F}(\mathrm{mg} / \mathrm{g}(\mathrm{L} / \mathrm{mg}),(1 / \mathrm{n})$ is the adsorption capacity of the sorbent and $\mathrm{n}$ giving an indication of how favorable the adsorption process. The magnitude of the exponent, $1 / \mathrm{n}$, gives an indication of the favorability of adsorption. Table 2

The Value of $K_{F}$ and $n$ are calculated from the intercept and slope of the plot (Figure. 9) and listed in

The plot of amount adsorbed (Ln qe) against the equilibrium concentration (Ln Ce). (Figure. 9) shows that the adsorption obeys the Freundlich model. [29; 30]. 
- The Temkin isotherm model

Temkin and Pyzhev considered the effects of some indirect sorbate/adsorbate interactions on adsorption isotherms and suggested that because of these interactions the heat of adsorption of all the molecules in the layer would decrease linearly with coverage [31].

The Temkin isotherm has been used in the following form.

$$
q_{e}=B \times \ln A+B \times \ln C_{e} \quad \text { eq } 8
$$

Where $\mathrm{B}=\mathrm{R}^{*} \mathrm{~T} / \mathrm{K}_{\mathrm{T}}, \mathrm{K}_{\mathrm{T}}$ is the Temkin constant related to heat of sorption $(\mathrm{J} / \mathrm{mol})$; $\mathrm{A}$ is the Temkin isotherm constant $(\mathrm{L} / \mathrm{g}), \mathrm{R}$ the gas constant $\left(8.314 \mathrm{~J} / \mathrm{mol}^{\circ} \mathrm{K}\right)$ and $\mathrm{T}$ the absolute temperature $\left({ }^{\circ} \mathrm{K}\right)$. Therefore, by plotting qe vs Ln Ce (Figure. 10) the constants A and B can be determined. The constants A and B are listed in Table 2.

\section{- Dubinin-Radushkevich (D-R) isotherm model}

The equilibrium data were also applied to the Dubinin-Radushkevich (D-R) isotherm model to determine if adsorption occurred by physical or chemical processes.

The linearized form of the $\mathrm{D}-\mathrm{R}$ isotherm $[32 ; 33]$ is as follows:

$$
\ln q_{e}=\ln q_{m}-\beta \times \varepsilon^{2} \quad \text { eq9 }
$$

Where $\beta$ is the activity coefficient related to mean adsorption energy $\left(\mathrm{mol}^{2} / \mathrm{J}^{2}\right)$ and $\varepsilon$ is the Polanyi potential

$$
\varepsilon^{2}=R \times T \times \ln \left(1+\frac{1}{C_{e}}\right) \quad \text { eq10 }
$$

The $\mathrm{D}-\mathrm{R}$ isotherm is applied to the data obtained from the empirical studies.

The mean adsorption energy, $\mathrm{E}(\mathrm{kJ} / \mathrm{mol})$ is as follows:

$$
E=\frac{1}{\sqrt{-2 \beta}} \quad \text { eq11 }
$$

As seen in Table 2, the Freundlich isotherm fits quite well with the experimental data.

Examination of the plot suggests that the linear Freundlich isotherm is a good model for the sorption of the Methylene blue onto Na-bentonite. Table 2 shows the linear Freundlich sorption isotherm constants, coefficients of determination $\left(\mathrm{R}^{2}\right)$ and error values. Based on the $\mathrm{R}^{2}$ values, (correlation coefficient $\mathrm{R}^{2}>$ ). The linear form of the Freundlich isotherm appears to produce a reasonable model for sorptions in all three ratios, implying the presence of the highly energetic sites were the molecules of methylene blue were adsorbed. After the point of inflection of the experimental data, the Freundlich isotherm predicted that the equilibrium adsorption capacity should keep increasing exponentially with increasing equilibrium concentration in the liquid phase.

However, the experimental adsorption isotherm for methylene blue presented a plateau at higher equilibrium concentration, implying the saturation of adsorption sites and the maximum filling of the pores. Thus, Freundlich model should not be used for extrapolation of this data to higher concentration (problem of high-saturation), [34].

\section{III-5. Desorbability}

The adsorption and desorption isotherm of thymol on pillared clays was presented in (Figure. 11).

In this study, the pillared clay and thymol interaction was partly non-reversible, in water and in the same conditions of equilibrium adsorption:

The higher adsorption affinity of methylene blue is attributed to stronger hydrophilic interaction between the positives and negatives charges of the surface and the $\mathrm{MB}^{+}$cation (dipoles interactions).

The (Figure. 11) also show that there was no appreciable desorption resistant fraction of methylene blue in Na-bentonite after desorptions. This figure shows that methylene blue was more resistant for desorption. A solute with higher Kow-exhibited a higher sorption affinity and a higher resistance for desorption in Nabentonite. The resistance of the desorption is very low because the binding is due to adsorption by a cation exchange and the ionic interaction between an organic cation and the negative surface of the carrier (chemical adsorption) to making fastening connections between the MB and the highest surface areaIn order to study.

\section{III-6. The adsorption mechanism}

The mechanism of sorption and potential rate determining steps, different kinetic models have been used to test experimental data obtained from 2 process variables (initial MB concentration). The sorption dynamics of the adsorption by Na-bentonite were tested with the Largergren pseudo-first model, proposed in 
1898 order [35; 36] the chemisorptions pseudo-second order [37], Elovich kinetic model [38], the intra-particle diffusion model [39], and liquid film diffusion model [40].

\section{- Pseudo-first order model}

The adsorption kinetics can be described by a pseudo-first order equation as suggested by Lagergren:

$$
\frac{d q}{d t}=K_{1} \times\left(q_{e}-q_{t}\right)
$$

Where; $\mathrm{K}_{1}$ (min-1) is the rate constant of the pseudo-first order model and qe and qt are the sorption capacity at equilibrium and at time $\mathrm{t}$, respectively $(\mathrm{mg} / \mathrm{g})$.

After the integration applying boundary conditions, viz that the initial conditions are

$$
\begin{gathered}
\left(\mathrm{q}_{\mathrm{e}}-\mathrm{q}_{\mathrm{t}}\right)=0 \text { at } t=0, \text { equation becomes: } \\
\ln \left(q_{e}-q_{t}\right)=\ln q_{e}-k_{1} \cdot t \quad \text { eq12 }
\end{gathered}
$$

The values of $\log (q e-q t)$ were linearly correlated with $t$. The plot of $\log (q e-q t)$ versus $t$ should give a linear relationship from which $\mathrm{K}_{1}$ and qe can be determined from the slop and intercept of the plot, respectively [ $41 ; 42]$. The applicability of the pseudo-first order equation to experimental data generally, differs in two ways; the parameter does not represent the number of available sites and the parameter log (qe) is an adjustable parameter and often found not equal to the intercept of the plot $\log (\mathrm{qe}-\mathrm{qt})$ versus $\mathrm{t}$, whereas in true first order, $\log$ (qe) should be equal to the interception.

Figure 12 depict the pseudo-first order plots at different initial concentration and the constant parameters are shown in Table 2.

\section{- Pseudo-second order model}

The pseudo-second order equation developed by Ho can be written as

$$
\frac{d q}{d t}=K_{2} \times\left(q_{e}-q_{t}\right) 2 \quad \text { eq14 }
$$

Where; $\mathrm{K} 2\left(\mathrm{~g} \mathrm{mg}^{-1} \mathrm{~min}^{-1}\right)$ is the rate constant of the pseudo-second order. Integrating Equation (14) for the boundary conditions $\mathrm{t}=0$ to $\mathrm{t}=\mathrm{t}$ and $\mathrm{q}=0$ to $\mathrm{q}=\mathrm{qe}$ gives:

$$
\frac{1}{\left(q_{e}-q_{t}\right)}=\frac{1}{q_{e}}+K_{2} \times t \quad \quad \text { eq } 15
$$

Which has a linear form of :

$$
\frac{t}{q_{t}}=\frac{1}{k_{2} \cdot q_{e}^{2}}+\frac{1}{q_{e}} \times t \quad \quad \text { eq } 16
$$

$\mathrm{K}_{2}$ and qe can be obtained from the intercept and slope of plotting $\frac{\mathrm{t}}{\mathrm{q}_{\mathrm{t}}} \mathrm{vs} \mathrm{t}$

The fit of the experimental data to pseudo second order kinetic model at different initial concentration are shown in Figure 13, [41; 42]. The constant parameters are shown in Table 2.

\section{- Elovich model (G“"unay et al., 2007)}

In reactions involving chemisorption of adsorbate on a solid surface without desorption of products, adsorption rate decreases with time due to an increased surface coverage. One of the most useful models for describing such 'activated' chemi-sorption is the Elovich equation [43]. The Elovich equation can be written as [35]:

$$
q_{t}=\frac{1}{\alpha} \times \operatorname{Ln}(\alpha \beta)+\frac{1}{\alpha} \times \operatorname{Ln}(t) \quad \text { eq17 }
$$

Where; $\alpha$ is the initial adsorption rate, and $\beta$ is the desorption constant during each experiment.

The fit of the experimental data to Elovich kinetic model at different initial concentration are shown in Figure 14. The constant parameters are shown in Table 2. 


\section{- Macro and micro-pore diffusion}

The mechanism of adsorption of a sorbate on a sor-bent follows a series of steps. The slowest of these steps control the overall rate of the process. Generally, pore and intra-particle diffusion are often-rate limiting in a batch reactor while, for a continuous flow system, film diffusion is more likely the rate limiting step [44]. Though there is a high possibility for pore diffusion to be the rate limiting step in a batch process, the adsorption rate parameter, which controls the batch process for most of the contact time, is the intra-particle diffusion [39; 19]. The most widely applied intraparticle diffusion equation for sorption system is given by Weber and Morris (1963) [39].

\section{- The intra-particle diffusion model I and II}

Several steps are involved in the sorption of sorbate by a sorbent. These involve transport of the solute molecules from the aqueous phase to the surface of the solid particulates and diffusion of the so-lute molecules into the interior of the pores, which is usually a slow process [19].

The intra-particle diffusion rate constant (kid) is given by the following equation:

$$
q_{t}=k_{i d} \times t^{0.5} \quad \text { eq18 }
$$

The fit of the experimental data to intra-particle diffusion I \& II order kinetic model at different initial concentration are shown in (Figure $15 \& 16$ ). The constant parameters are shown in Table 3.

When intra-particle diffusion plays a significant role in controlling the kinetics of the sorption process, the plots of qt versus $\mathrm{t}^{0.5}$ yield straight lines passing through the origin and the slope gives the rate constant kid.

Another type of intra-particle diffusion model is expressed as $[39 ; \mathbf{4 5}]$ :

$$
R=K_{i d} \times t^{a} \quad \text { eq19 }
$$

A linearised form of the equation is given as J. C. Igwe, and A. A. Abia [46]:

$$
\operatorname{Ln}(R)=\operatorname{Ln}\left(K_{i d}\right)+a \times \operatorname{Ln}(t) \quad \text { eq20 }
$$

Where, $\mathrm{R}$ is the fraction of the amount adsorbed, $\mathrm{t}$ is the contact time (min) ' $\mathrm{a}$ ' is the gradient of linear plots; Kid is the intra-particle diffusion rate constant $\left(\mathrm{min}^{-1}\right)$.

\section{- Liquid film diffusion model}

However, when the transport of the solute molecules from the liquid phase up to the solid phase, boundary plays the most significant role in adsorption; the liquid film diffusion model may be applied as follows:

$$
\operatorname{Ln}(1-F)=-k_{f d} \times t \quad \text { eq2 } 1
$$

where $\mathrm{F}$ is the fractional attainment of equilibrium $\mathrm{F}=\frac{\mathrm{q}_{\mathrm{t}}}{\mathrm{q}_{\mathrm{e}}}$ and $\mathrm{Kfd}$ is the adsorption rate constant. A linear plot of $-\ln (1-\mathrm{F}) V S \mathrm{t}$ with zero intercept would suggest that the kinetics of the sorption process is controlled by diffusion through the liquid film surrounding the solid sorbent [19].

The fit of the experimental data to the liquid film diffusion kinetic model at different initial concentration are shown in (Figure 17). The constant parameters are shown in Table 3.

Three kinetic models; pseudo-first order, pseudo-second order and Elovich models were used to fit experimental data to examine the adsorption kinetics.

The pseudo first order rate constant, $\mathrm{K}_{1}$ ranged between $6.4210^{-2}$ to $1.39110^{-2}$ (Table 3). The result showed clearly that $\mathrm{K}_{1}$ is independent of initial concentration.

Similar result has been presented in literature $[47 ; 48]$. However, the experimental adsorption capacity was observed to increase with increased initial Concentration (Table 3).

The pseudo first order theoretical qe values, obtained from the intercept of the linear plots, were compared with the experimental qe values (Table 3 ).

The pseudo first order kinetic model suffered from inadequacies when applied to MB sorption on B-Na at varying MB concentrations. The experimental qe values differ from the corresponding theoretical values. Discrepancies of this nature have been reported [37]. Owing to the low linearity of the plots

obtained from this study and the discrepancies noted in the theoretical and experimental values of qe, chemisorptions pseudo second order kinetic model was also used to test the data obtained from the same studies.

It is seen that the pseudo-second order model well represented the experimental data $\left(\mathrm{R}^{2}>\right.$ 0.99997). Similar results have been observed in the adsorption of methylene blue onto dehydrated wheat bran carbon [49], montmorillonite super adsorbent nanocomposite [50].

The value of the pseudo second order rate constant $\mathrm{K}_{2}$ was found to generally decrease as the initial concentration increased from. Increasing MB concentration in solution seems to reduce the diffusion of MB in the boundary layer and to enhance the diffusion in the solid. 
The value of $\mathrm{K}_{2}$, on the other hand, increased from $8.6710^{-3}$ to $3.4410^{-2}$ as the temperature increases, confirming that the adsorption process is endothermic in nature. The increase in value of $\mathrm{K}^{2}$ with temperature is due to increased mobility of the. It can also be seen from the Table 3 that the equilibrium sorption capacity qe (cal) it's the seem to corresponding theoretical values.

The values of the constants " $K_{\mathrm{id}}$ "and " $\mathrm{a}$ ", are shown on Table 4 . The values of ' $\mathrm{a}$ ' and $\mathrm{K}_{\mathrm{id}}$ were calculated from the slopes and intercepts of the plot respectively. The values of ' $a$ ' depicts the adsorption mechanism and $K_{\text {id }}$ may be taken as a rate factor [51].

A relatively high $\mathrm{R}^{2}$ value of Intraparticle diffusion model I indicates that the model successfully describes the mechanism of adsorption kinetics.

If the regression of qt versus $t^{1 / 2}$ is linear and passes through the origin, then intra-particle diffusion is the slaw rate-limiting step. However, the linear plots (Figure. 15) at each concentration did not pass through the origin. This indicates that the intra-particle diffusion was not only rate controlling step. So the multiple nature observed in the intra-particle diffusion plot suggests that intra-particle diffusion is not solely (18 min for equilibrium) rate controlling. External mass transfer of $\mathrm{MB}$ molecules on to pillared clay is also significant in the sorption process, especially at the initial reaction period ( $75 \%$ of amount adsorbed in the first $10 \mathrm{~min}$ ).

IV. Figures and Tables

Table 1: Chemical composition (wt \%) of sodium modified and Raw bentonite

\begin{tabular}{cccccccccccc}
\hline Oxides & $\mathrm{SiO}_{2}$ & $\mathrm{Al}_{2} \mathrm{O}_{3}$ & $\mathrm{CaO}$ & $\mathrm{MgO}$ & $\mathrm{Fe}_{2} \mathrm{O}_{3}$ & $\mathrm{Na}_{2} \mathrm{O}_{2}$ & $\mathrm{~K}_{2} \mathrm{O}$ & $\mathrm{SO}_{3}$ & $\mathrm{CuO}$ & $\mathrm{TiO}_{2}$ & $\mathrm{ZnO}$ \\
\hline Na-B & 61.17 & 15.13 & 4.00 & 6.00 & 3.25 & 1.1 & 0.52 & 0.38 & 0.13 & 0.12 & 0.1 \\
\hline Raw-B & 64.05 & 16.33 & 4.13 & 6.69 & 3.44 & 1.12 & 0.65 & 0.37 & 0.09 & 0.1 & 0.05 \\
\hline
\end{tabular}

Table 2. Isotherm parameters for adsorption of Methylene Blue on Na-bentonite

\begin{tabular}{|c|c|c|c|c|c|c|}
\hline \multicolumn{7}{|c|}{ LANGUMIUR ADSORPTION ISOTHERM: } \\
\hline & $\mathbf{R}^{2}$ & & Value & Standard Error & $\mathbf{K}_{\mathbf{L}}$ & $\mathbf{q m}$ \\
\hline$R_{S / L}=0.13 \%$ & 0.562 & $\begin{array}{c}\text { Intercept } \\
\text { Slope }\end{array}$ & $\begin{array}{c}0.11452 \\
-6.11910^{-4}\end{array}$ & $\begin{array}{c}0.0044 \\
2.69872 \quad 10^{-4}\end{array}$ & 1.7024 & 133.511 \\
\hline$R_{S / L}=0.16 \%$ & 0.562 & $\begin{array}{l}\text { Intercept } \\
\text { Slope }\end{array}$ & $\begin{array}{c}0.15381 \\
4.676910^{-4}\end{array}$ & $\begin{array}{c}0.01291 \\
8.6798710^{-4}\end{array}$ & 0.4769 & 162.415 \\
\hline$R_{S / L}=0.25 \%$ & 0.760 & $\begin{array}{l}\text { Intercept } \\
\text { Slope }\end{array}$ & $\begin{array}{r}0.80354 \\
-0.01198 \\
\end{array}$ & $\begin{array}{l}0.11628 \\
0.00475 \\
\end{array}$ & 0.0278 & 309.00 \\
\hline \multicolumn{7}{|c|}{ FREUNDLICH ADSORPTION ISOTHERM : } \\
\hline & $\mathbf{R}^{2}$ & & Value & Standard Error & $\mathbf{K}_{\mathbf{F}}$ & $\mathbf{n}$ \\
\hline$R_{S / L}=0.13 \%$ & 0.99642 & $\begin{array}{l}\text { Intercept } \\
\text { Slope }\end{array}$ & $\begin{array}{l}2.06587 \\
1.07325\end{array}$ & $\begin{array}{l}0.07405 \\
0.02875\end{array}$ & 7.8921 & 0.9317 \\
\hline$R_{S / L}=0.16 \%$ & 0.98202 & $\begin{array}{l}\text { Intercept } \\
\text { Slope }\end{array}$ & $\begin{array}{c}1.93043 \\
0.9602\end{array}$ & $\begin{array}{l}0.15793 \\
0.06482\end{array}$ & 6.8924 & 1.0414 \\
\hline$R_{S / L}=0.25 \%$ & 0.97438 & $\begin{array}{l}\text { Intercept } \\
\text { Slope }\end{array}$ & $\begin{array}{r}-0.87315 \\
1.50935 \\
\end{array}$ & $\begin{array}{c}0.42709 \\
0.1407 \\
\end{array}$ & 0.4176 & 0.6625 \\
\hline \multicolumn{7}{|c|}{ TEMKIN ADSORPTION ISOTHERM: } \\
\hline & $\mathbf{R}^{2}$ & & Value & Standard Error & $\alpha$ & $\boldsymbol{\beta}$ \\
\hline $\mathrm{R}_{\mathrm{S} / \mathrm{L}}=\mathbf{0 . 1 3 \%}$ & 0.93021 & $\begin{array}{l}\text { Intercept } \\
\text { Slope }\end{array}$ & $\begin{array}{c}-174.3102 \\
126.8102\end{array}$ & $\begin{array}{l}38.52094 \\
14.09243\end{array}$ & 0.2529 & 126.8102 \\
\hline$R_{S / L}=0.16 \%$ & 0.91347 & $\begin{array}{l}\text { Intercept } \\
\text { Slope }\end{array}$ & $\begin{array}{l}-85.5257 \\
70.0163\end{array}$ & $\begin{array}{l}25.94616 \\
10.64966\end{array}$ & 0.2947 & 70.0163 \\
\hline$R_{S / L}=0.25 \%$ & 0.86794 & $\begin{array}{l}\text { Intercept } \\
\text { Slope }\end{array}$ & $\begin{array}{c}-152.9999 \\
67.27411 \\
\end{array}$ & $\begin{array}{l}44.86613 \\
14.78034 \\
\end{array}$ & 0.1028 & 67.27411 \\
\hline \multicolumn{7}{|c|}{ DUBININ-RADUSHKEVICH ADSORPTION ISOTHERM: } \\
\hline & $\mathbf{R}^{2}$ & & Value & Standard Error & $\boldsymbol{\beta}$ & $\mathbf{E}(\mathrm{kj} / \mathrm{mol})$ \\
\hline $\mathrm{R}_{\mathrm{S} / \mathrm{L}}=\mathbf{0 . 1 3 \%}$ & 0.835 & $\begin{array}{l}\text { Intercept } \\
\text { Slope }\end{array}$ & $\begin{array}{c}5.23476 \\
-6.559410^{-6}\end{array}$ & $\begin{array}{c}0.17333 \\
1.456910^{-6}\end{array}$ & $-6.55910^{-6}$ & 276.0998 \\
\hline$R_{S / L}=0.16 \%$ & 0.871 & $\begin{array}{l}\text { Intercept } \\
\text { Slope }\end{array}$ & $\begin{array}{c}4.5388 \\
-5.1127 \quad 10^{-6}\end{array}$ & $\begin{array}{c}0.19818 \\
1.3890310^{-6}\end{array}$ & $-5.11210^{-6}$ & 312.7444 \\
\hline$R_{\mathrm{S} / \mathrm{L}}=0.25 \%$ & 0.922 & $\begin{array}{l}\text { Intercept } \\
\text { Slope }\end{array}$ & $\begin{array}{c}4.77112 \\
-5.053610^{-5} \\
\end{array}$ & $\begin{array}{c}0.12635 \\
6.56023 \quad 10^{-6}\end{array}$ & $-5.05310^{-5}$ & 99.4741 \\
\hline
\end{tabular}

Table 3 : Comparison of the pseudo-first \& second order, and Elovich model adsorption rate constants of Methylene Blue on Na-bentonite

\begin{tabular}{|c|c|c|c|c|c|c|c|}
\hline \multicolumn{8}{|c|}{ PSEUD FIRST ORDER KINETIC } \\
\hline $\mathrm{C}(\mathbf{m g} / \mathbf{L})$ & $\boldsymbol{R}^{2}$ & & Value & Stand Err & $K_{1}$ & $\boldsymbol{q}_{\text {e calcu }}$ & $\boldsymbol{q}_{\text {exp }}$ \\
\hline \multirow{2}{*}{$C_{1}=3.63$} & \multirow{2}{*}{0.92624} & Intercept & 3.69217 & 0.26972 & \multirow{2}{*}{0.06422} & \multirow{2}{*}{40.1318} & \multirow{2}{*}{28.72087} \\
\hline & & Slope & -0.06422 & 0.00897 & & & \\
\hline \multirow{2}{*}{$C_{2}=4.00$} & \multirow{2}{*}{0.97573} & Intercept & 4.27423 & 0.33171 & \multirow{2}{*}{0.1174} & \multirow{2}{*}{71.8248} & \multirow{2}{*}{23.935} \\
\hline & & Slope & -0.1174 & 0.01301 & & & \\
\hline $\mathrm{C}_{3}=\mathbf{5 . 0 1}$ & 0.9227 & Intercept & 3.74126 & 0.3432 & 0.06765 & 42.151 & 30.85865 \\
\hline
\end{tabular}


Adsorption-desorption and kinetics studies of Methylene Blue Dye on Na-bentonite from Aqueous

\begin{tabular}{|c|c|c|c|c|c|c|c|}
\hline & & Slope & -0.06765 & 0.01115 & & & \\
\hline $\mathrm{C}_{4}=\mathbf{8 . 0 0}$ & 0.96103 & $\begin{array}{c}\text { Intercept } \\
\text { Slope }\end{array}$ & $\begin{array}{c}4.3529 \\
-0.09109\end{array}$ & $\begin{array}{l}0.42909 \\
0.01284\end{array}$ & 0.09109 & 77.7034 & 33.65415 \\
\hline$C_{5}=10.00$ & 0.80739 & $\begin{array}{c}\text { Intercept } \\
\text { Slope }\end{array}$ & $\begin{array}{c}6.14231 \\
-0.13916\end{array}$ & $\begin{array}{l}0.83265 \\
0.03777\end{array}$ & 0.13916 & 465.126 & 220.38934 \\
\hline $\mathrm{C}_{6}=\mathbf{2 0 . 6 5}$ & 0.91127 & $\begin{array}{c}\text { Intercept } \\
\text { Slope }\end{array}$ & $\begin{array}{c}5.33095 \\
-0.12298 \\
\end{array}$ & $\begin{array}{c}0.68738 \\
0.0218 \\
\end{array}$ & 0.12298 & 206.634 & 61.7186 \\
\hline \multicolumn{8}{|c|}{ PSEUD SECOND ORDER KINETIC } \\
\hline $\mathrm{C}(\mathbf{m g} / \mathbf{L})$ & $R^{2}$ & & Value & Stand Err & $\boldsymbol{K}_{2}$ & $q_{\text {e calc }}$ & $q_{\text {e expe }}$ \\
\hline$C_{1}=3.63$ & 0.99985 & $\begin{array}{c}\text { Intercept } \\
\text { Slope }\end{array}$ & $\begin{array}{l}0.13837 \\
0.03464\end{array}$ & $\begin{array}{c}0.04761 \\
1.392 \quad 10^{-4}\end{array}$ & 0.00867 & 28.868 & 28.72087 \\
\hline $\mathrm{C}_{2}=\mathbf{4 . 0 0}$ & 0.99998 & $\begin{array}{c}\text { Intercept } \\
\text { Slope }\end{array}$ & $\begin{array}{l}0.11871 \\
0.04167\end{array}$ & $\begin{array}{c}0.01779 \\
5.28 \quad 10^{-5}\end{array}$ & 0.01472 & 23.998 & 23.935 \\
\hline$C_{3}=5.01$ & 0.99999 & $\begin{array}{c}\text { Intercept } \\
\text { Slope }\end{array}$ & $\begin{array}{l}0.06312 \\
0.03234\end{array}$ & $\begin{array}{c}0.0149 \\
3.91210^{-5}\end{array}$ & 0.01657 & 30.9214 & 30.85865 \\
\hline $\mathrm{C}_{4}=\mathbf{8 . 0 0}$ & 1 & $\begin{array}{c}\text { Intercept } \\
\text { Slope }\end{array}$ & $\begin{array}{l}0.02562 \\
0.02969\end{array}$ & $\begin{array}{c}0.00684 \\
1.738 \quad 10^{-5}\end{array}$ & 0.03441 & 33.681 & 33.65415 \\
\hline$C_{5}=10.00$ & 0.99997 & $\begin{array}{c}\text { Intercept } \\
\text { Slope }\end{array}$ & $\begin{array}{l}0.00796 \\
0.00453\end{array}$ & $\begin{array}{c}0.00285 \\
8.148 \quad 10^{-6}\end{array}$ & 0.00258 & 220.75 & 220.38934 \\
\hline $\mathrm{C}_{6}=\mathbf{2 0 . 6 5}$ & 1 & $\begin{array}{c}\text { Intercept } \\
\text { Slope }\end{array}$ & $\begin{array}{l}0.01642 \\
0.01619\end{array}$ & $\begin{array}{c}0.00349 \\
1.03410^{-5}\end{array}$ & 0.01596 & 61.766 & 61.7186 \\
\hline \multicolumn{8}{|c|}{ ELOVICH MODEL (G"UNAY ET AL., 2007) } \\
\hline $\mathrm{C}(\mathbf{m g} / \mathbf{L})$ & $R^{2}$ & & Value & Stand Err & $\alpha$ & $\boldsymbol{\beta}$ & $q_{e e x p}$ \\
\hline $\mathrm{C}_{1}=\mathbf{3 . 6 3}$ & 0.85861 & $\begin{array}{c}\text { Intercept } \\
\text { Slope }\end{array}$ & $\begin{array}{l}-2.51757 \\
8.23509\end{array}$ & $\begin{array}{l}5.05312 \\
1.63753\end{array}$ & 0.6643 & 0.1214 & 28.72087 \\
\hline $\mathrm{C}_{2}=\mathbf{4 . 0 0}$ & 0.69567 & $\begin{array}{c}\text { Intercept } \\
\text { Slope }\end{array}$ & $\begin{array}{c}18.90164 \\
0.93733\end{array}$ & $\begin{array}{l}0.94797 \\
0.26587\end{array}$ & $1.516310^{8}$ & 1.0668 & 23.935 \\
\hline $\mathrm{C}_{3}=5.01$ & 0.93201 & $\begin{array}{c}\text { Intercept } \\
\text { Slope }\end{array}$ & $\begin{array}{l}9.51337 \\
5.36257\end{array}$ & $\begin{array}{l}2.36787 \\
0.71768\end{array}$ & $7.263710^{4}$ & 0.1864 & 30.85865 \\
\hline $\mathrm{C}_{4}=\mathbf{8 . 0 0}$ & 0.90762 & $\begin{array}{c}\text { Intercept } \\
\text { Slope }\end{array}$ & $\begin{array}{c}28.68704 \\
1.06478\end{array}$ & $\begin{array}{l}0.63629 \\
0.16773\end{array}$ & $3.06110^{12}$ & 0.9392 & 33.65415 \\
\hline $\mathrm{C}_{5}=\mathbf{1 0 . 0 0}$ & 0.63848 & $\begin{array}{c}\text { Intercept } \\
\text { Slope }\end{array}$ & $\begin{array}{l}57.47781 \\
42.97636\end{array}$ & $\begin{array}{c}4.41254 \\
13.70708\end{array}$ & $3.95110^{26}$ & 0.0232 & 220.38934 \\
\hline $\mathrm{C}_{6}=\mathbf{2 0 . 6 5}$ & 0.63626 & $\begin{array}{c}\text { Intercept } \\
\text { Slope }\end{array}$ & $\begin{array}{c}39.76319 \\
5.32025\end{array}$ & $\begin{array}{c}5.7954 \\
1.56919\end{array}$ & $9.88510^{17}$ & 0.1879 & 61.7186 \\
\hline
\end{tabular}

Table 4 : Comparison of the intra-particle I\&II, and Elovich model adsorption rate constants of

Methylene Blue on Na-bentonite

\begin{tabular}{|c|c|c|c|c|c|c|}
\hline \multicolumn{7}{|c|}{ INTRAPARTICLE DIFFUSION MODEL I } \\
\hline $\mathrm{C}(\mathrm{mg} / \mathrm{L})$ & $R^{2}$ & & Value & Stand Err & $K_{i d}$ & $C$ \\
\hline $\mathrm{C}_{1}=3.63$ & 0.98834 & $\begin{array}{c}\text { Intercept } \\
\text { Slope }\end{array}$ & $\begin{array}{l}0.22297 \\
4.73599\end{array}$ & $\begin{array}{l}3.42687 \\
0.84621\end{array}$ & 4.73599 & 0.22297 \\
\hline$C_{2}=4.00$ & 0.97375 & $\begin{array}{c}\text { Intercept } \\
\text { Slope }\end{array}$ & $\begin{array}{l}3.84771 \\
3.30439\end{array}$ & $\begin{array}{l}4.52956 \\
0.94448\end{array}$ & 3.30439 & 3.84771 \\
\hline$C_{3}=5.01$ & 0.98660 & $\begin{array}{l}\text { Intercept } \\
\text { Slope }\end{array}$ & $\begin{array}{l}4.35149 \\
425459\end{array}$ & $\begin{array}{l}3.70755 \\
0.82086\end{array}$ & 4.25459 & 4.35149 \\
\hline $\mathrm{C}_{4}=8.00$ & 0.96492 & $\begin{array}{l}\text { Intercept } \\
\text { Slope }\end{array}$ & $\begin{array}{c}7.41039 \\
3.877\end{array}$ & $\begin{array}{l}7.44587 \\
1.33732\end{array}$ & 3.877 & 7.41039 \\
\hline $\mathrm{C}_{5}=10.00$ & 0.98722 & $\begin{array}{l}\text { Intercept } \\
\text { Slope }\end{array}$ & $\begin{array}{l}12.45934 \\
40.43332\end{array}$ & $\begin{array}{c}29.63046 \\
7.60005\end{array}$ & 40.43332 & 12.45934 \\
\hline
\end{tabular}


Adsorption-desorption and kinetics studies of Methylene Blue Dye on Na-bentonite from Aqueous

\begin{tabular}{|c|c|c|c|c|c|c|}
\hline$C_{6}=20.65$ & 0.9793 & $\begin{array}{l}\text { Intercept } \\
\text { Slope }\end{array}$ & $\begin{array}{c}10.52232 \\
8.11977 \\
\end{array}$ & $\begin{array}{l}9.62182 \\
1.80763 \\
\end{array}$ & 8.11977 & 10.52232 \\
\hline \multicolumn{7}{|c|}{ INTRAPARTICLE DIFFUSION MODEL II } \\
\hline $\mathrm{C}(\mathbf{m g} / \mathbf{L})$ & $\boldsymbol{R}^{2}$ & & Value & Stand Err & $\boldsymbol{K}_{i d}$ & $a$ \\
\hline$C_{1}=3.63$ & 0.90606 & $\begin{array}{l}\text { Intercept } \\
\text { Slope }\end{array}$ & $\begin{array}{c}2.71705 \\
-1.39521\end{array}$ & $\begin{array}{l}0.64636 \\
0.14889\end{array}$ & 15.1356 & -1.3952 \\
\hline$C_{2}=4.00$ & 0.83778 & $\begin{array}{l}\text { Intercept } \\
\text { Slope }\end{array}$ & $\begin{array}{r}1.90909 \\
-1.13209\end{array}$ & $\begin{array}{c}0.67417 \\
0.1643\end{array}$ & 6.7469 & -1.1320 \\
\hline$C_{3}=5.01$ & 0.88675 & $\begin{array}{c}\text { Intercept } \\
\text { Slope }\end{array}$ & $\begin{array}{c}1.58499 \\
-1.12393\end{array}$ & $\begin{array}{l}0.66786 \\
0.15045\end{array}$ & 4.8792 & -1.1239 \\
\hline$C_{4}=8.00$ & 0.9434 & $\begin{array}{l}\text { Intercept } \\
\text { Slope }\end{array}$ & $\begin{array}{c}4.07898 \\
-1.85282\end{array}$ & $\begin{array}{l}0.85441 \\
0.22523\end{array}$ & 59.0851 & -1.8528 \\
\hline$C_{5}=10.00$ & 0.76734 & $\begin{array}{l}\text { Intercept } \\
\text { Slope }\end{array}$ & $\begin{array}{c}1.16449 \\
-1.13683\end{array}$ & $\begin{array}{l}0.84924 \\
0.20523\end{array}$ & 3.2042 & -1.1368 \\
\hline $\mathrm{C}_{6}=\mathbf{2 0 . 6 5}$ & 0.77218 & $\begin{array}{c}\text { Intercept } \\
\text { Slope }\end{array}$ & $\begin{array}{r}3.19666 \\
-1.72044 \\
\end{array}$ & $\begin{array}{l}1.25774 \\
0.30652 \\
\end{array}$ & 24.4507 & -1.7204 \\
\hline \multicolumn{7}{|c|}{ LIQUID FILM DIFFUSION MODEL } \\
\hline $\mathrm{C}(\mathrm{mg} / \mathrm{L})$ & $R^{2}$ & & Value & Stand Err & $K_{f d}$ & $C$ \\
\hline $\mathrm{C}_{1}=\mathbf{3 . 6 3}$ & 0.90513 & $\begin{array}{l}\text { Intercept } \\
\text { Slope }\end{array}$ & $\begin{array}{l}0.23453 \\
0.06434\end{array}$ & $\begin{array}{l}0.25301 \\
0.00922\end{array}$ & 0.06434 & 0.23453 \\
\hline$C_{2}=4.00$ & 0.79774 & $\begin{array}{l}\text { Intercept } \\
\text { Slope }\end{array}$ & $\begin{array}{l}1.00862 \\
0.04083\end{array}$ & $\begin{array}{c}0.5715 \\
0.01673\end{array}$ & 0.04083 & 1.00862 \\
\hline$C_{3}=5.01$ & 0.97579 & $\begin{array}{l}\text { Intercept } \\
\text { Slope }\end{array}$ & $\begin{array}{l}0.28228 \\
0.08259\end{array}$ & $\begin{array}{l}0.17854 \\
0.00648\end{array}$ & 0.08259 & 0.28228 \\
\hline$C_{4}=8.00$ & 0.68888 & $\begin{array}{l}\text { Intercept } \\
\text { Slope }\end{array}$ & $\begin{array}{c}1.0413 \\
0.05644\end{array}$ & $\begin{array}{l}0.69977 \\
0.01798\end{array}$ & 0.05644 & 1.0413 \\
\hline $\mathrm{C}_{5}=10.00$ & 0.65836 & $\begin{array}{l}\text { Intercept } \\
\text { Slope }\end{array}$ & $\begin{array}{c}0.9154 \\
0.07996\end{array}$ & $\begin{array}{c}0.6978 \\
0.02452\end{array}$ & 0.07996 & 0.9154 \\
\hline$C_{6}=20.65$ & 0.6899 & $\begin{array}{c}\text { Intercept } \\
\text { Slope }\end{array}$ & $\begin{array}{l}0.89604 \\
0.07732 \\
\end{array}$ & $\begin{array}{l}0.75853 \\
0.02221 \\
\end{array}$ & 0.07732 & 0.89604 \\
\hline
\end{tabular}

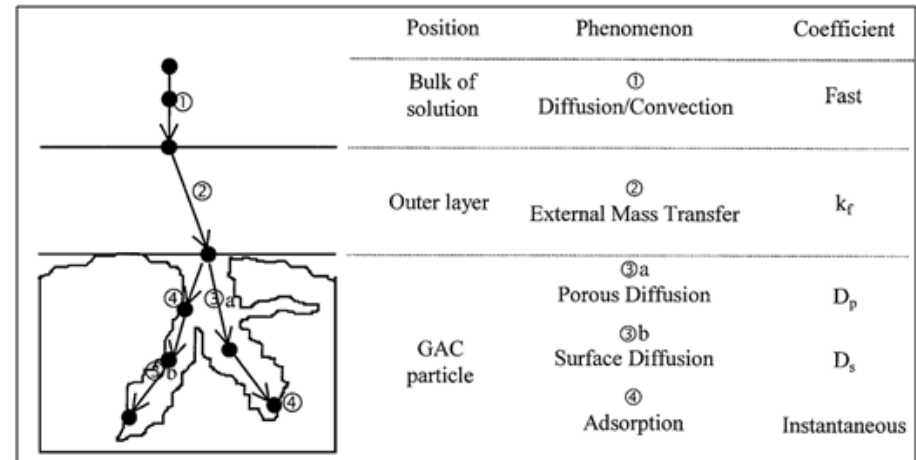

Figure 1. The four steps of adsorption (adapted from Weber and Smith, 1987)

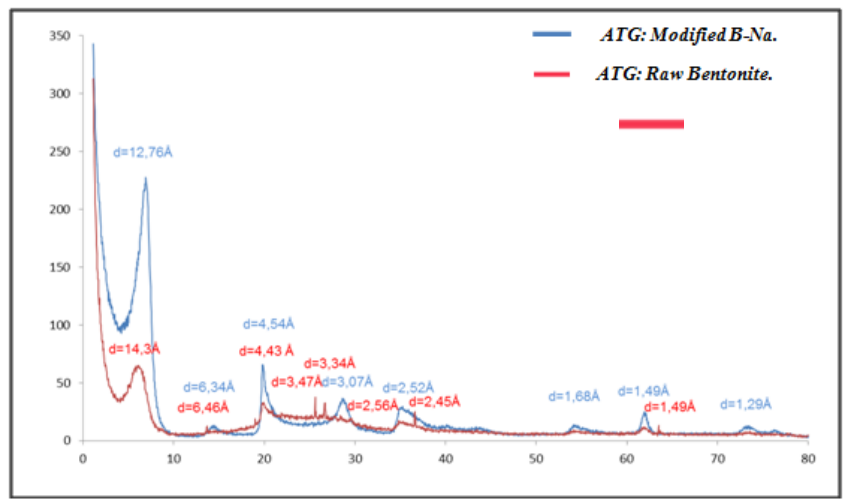

Figure.2. Diffractograms of the fine fraction powder of Raw and Sodium modified Bentonite 


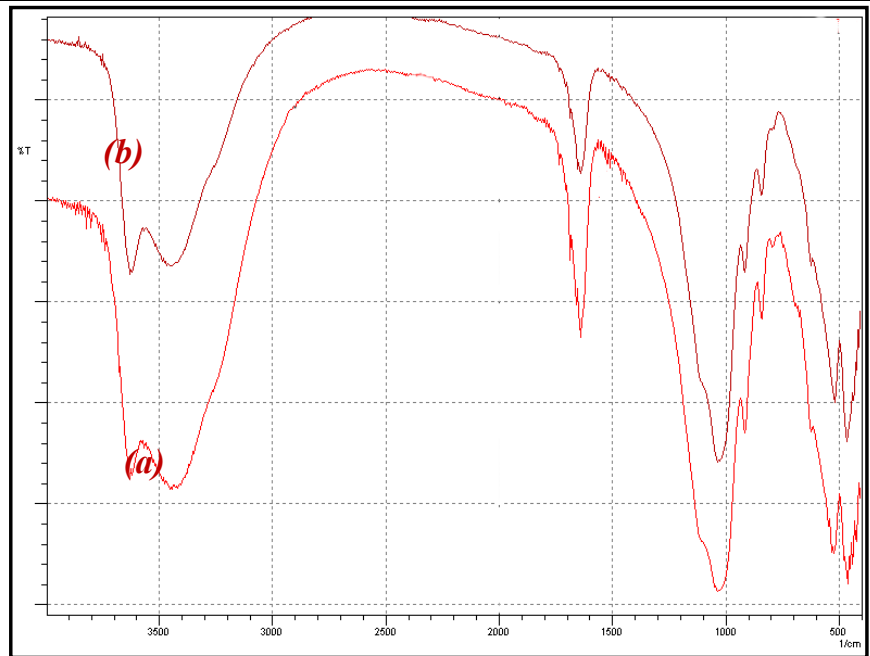

Figure.3. Infra-Red of Raw and Sodium modified Bentonite

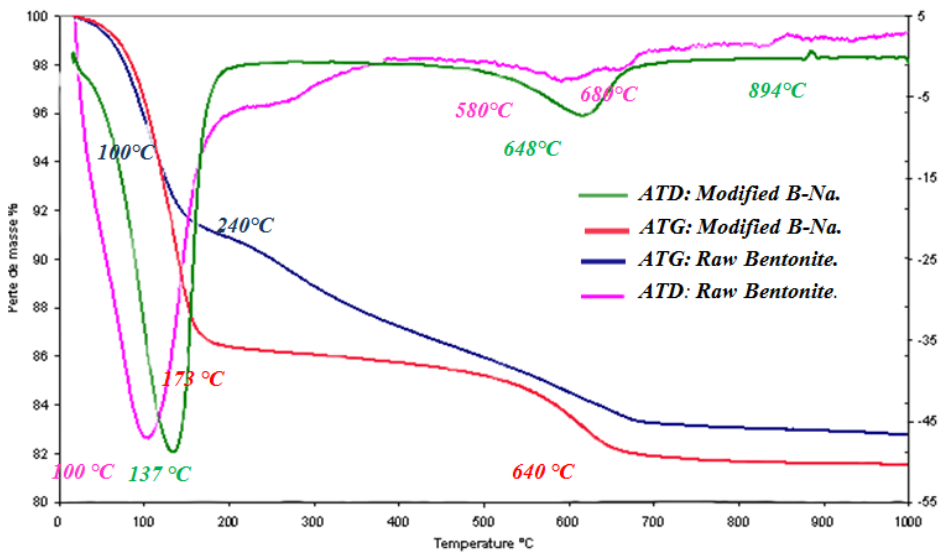

Figure.4. TDA \& TGA of sodium modified bentonite

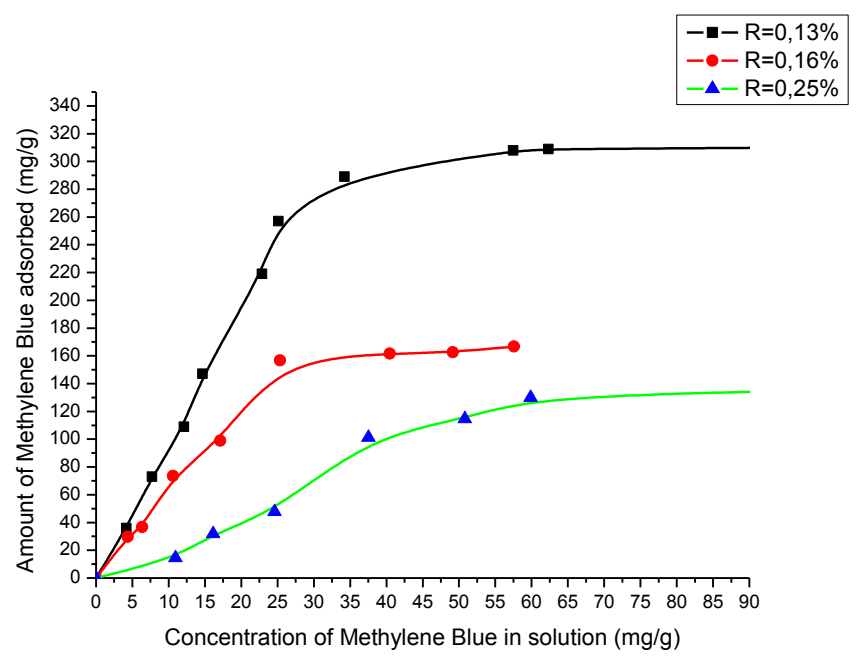

Figure:5. Equilibrium adsorption of Methylene Blue on Na-bentonite at different ratio solid / liquid 


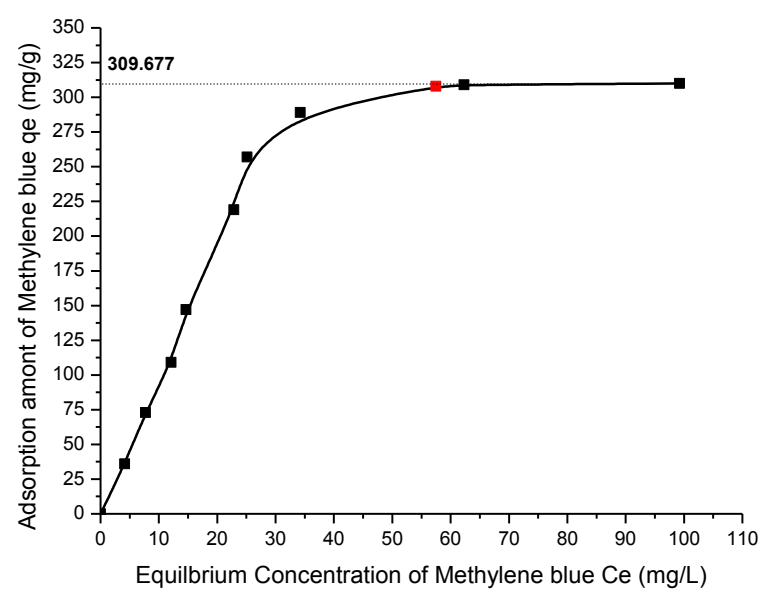

Figure:6. Equilibrium adsorption of Methylene Blue on Na-bentonite
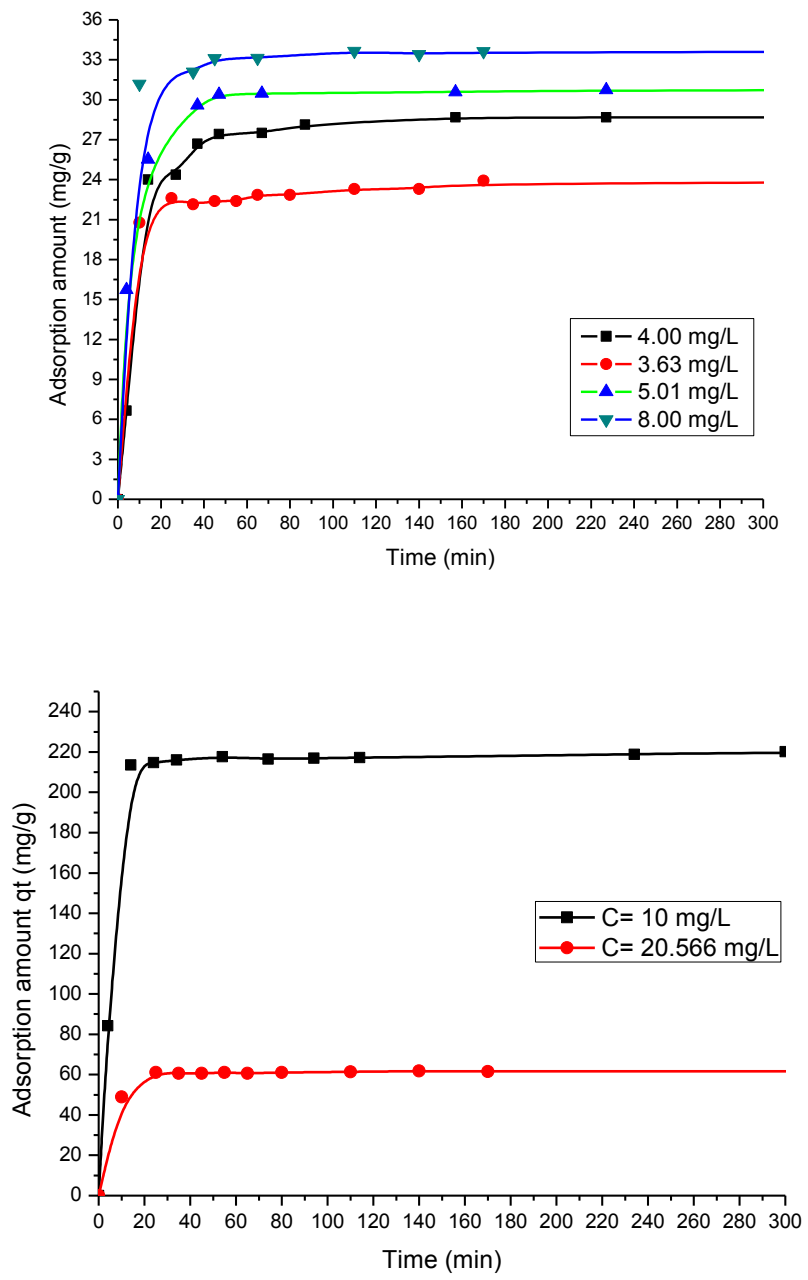

Figure: 7. Effect of initial concentration (mg/l) and time on the sorption of MB by Na-bentonite 


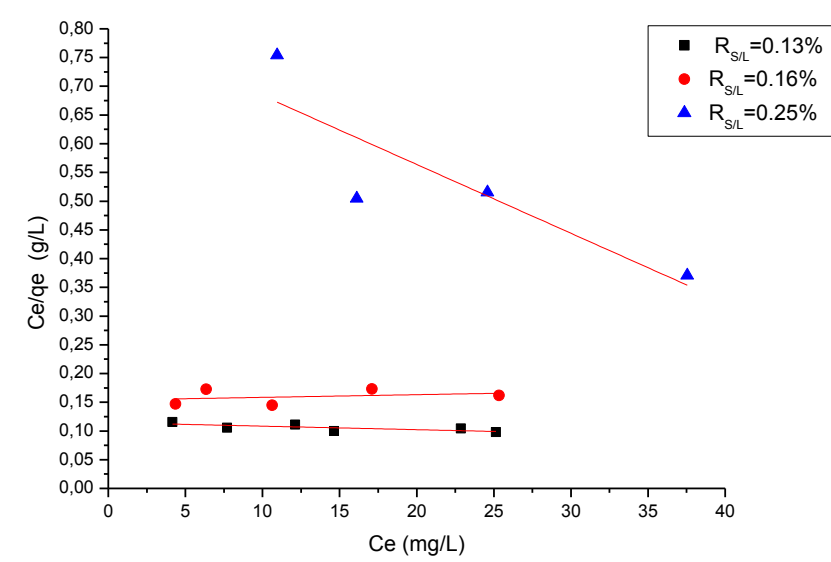

Figure. 8. Langmuir adsorption isotherm of Methylene Blue on Na-bentonite

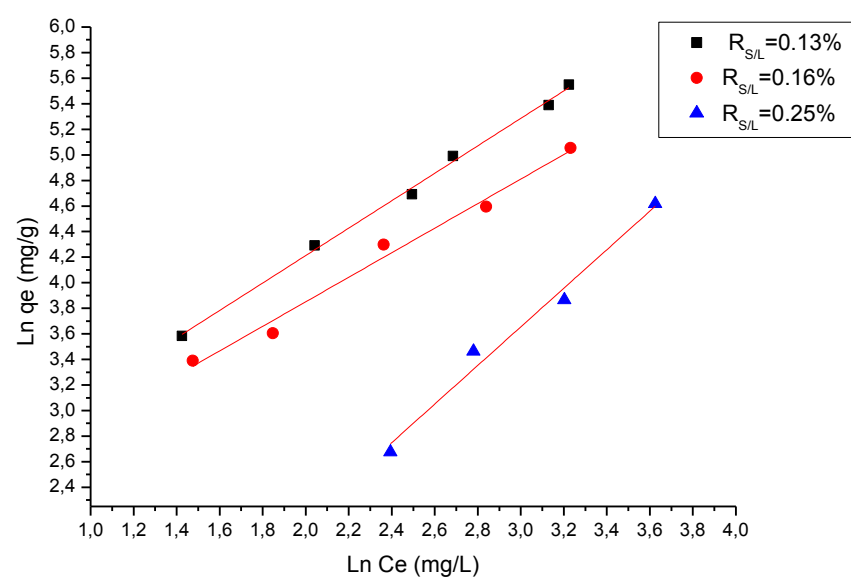

Fig. 9. Freundlich adsorption isotherm of Methylene Blue on Na-bentonite

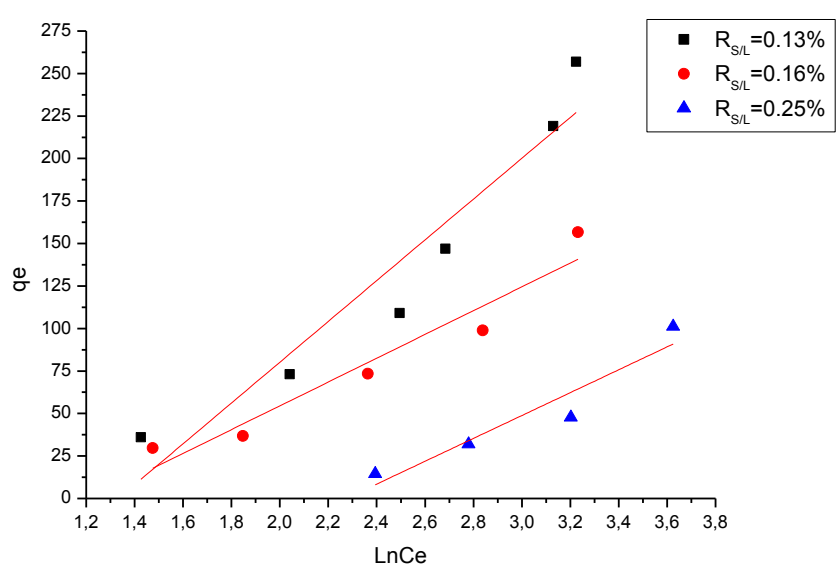

Fig.10. Temkin adsorption isotherm of thymol on pillared bentonite 


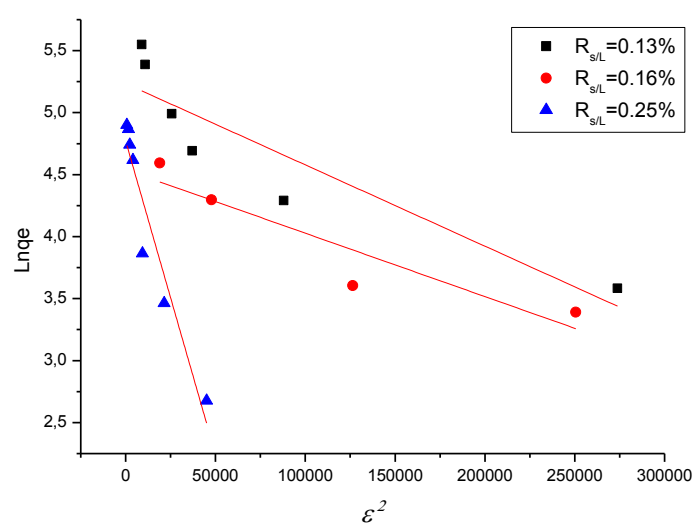

Figure.10. Dubinin-Radushkevich adsorption isotherm of Methylene blue on Na-bentonite

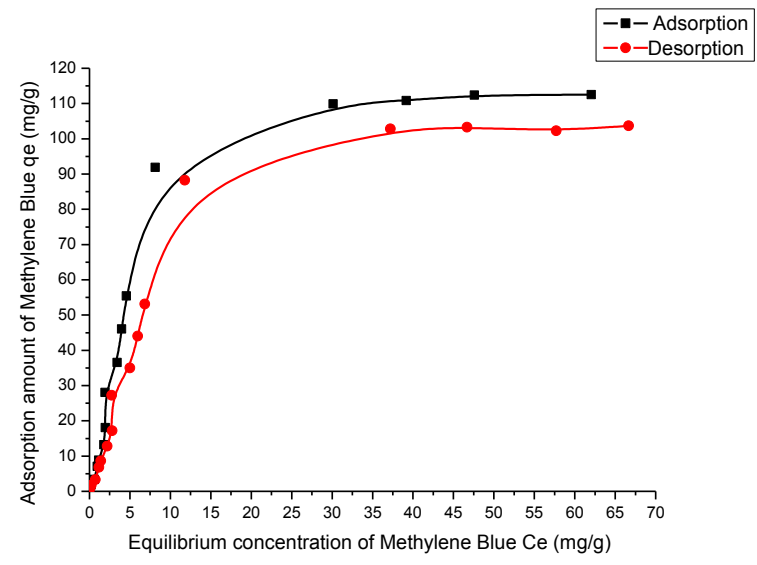

Figure:11. Equilibrium adsorption-desorption of Methylene Blue on Na-bentonite

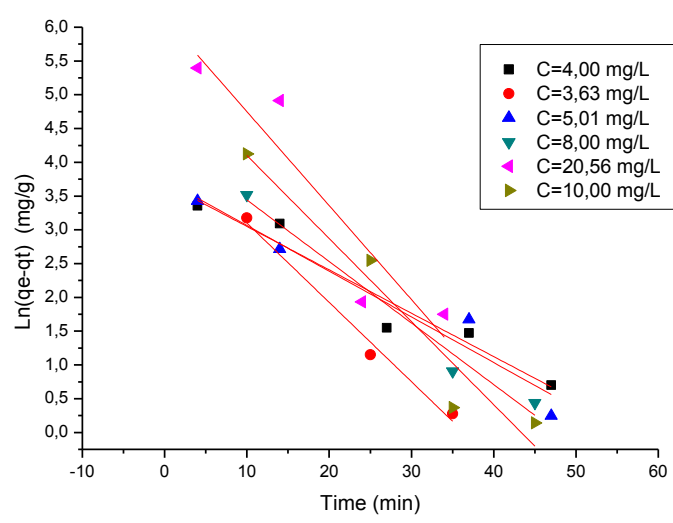

Figure:12 Pseudo-fist-order kinetic for adsorption of Methylene Blue on Na-bentonite 


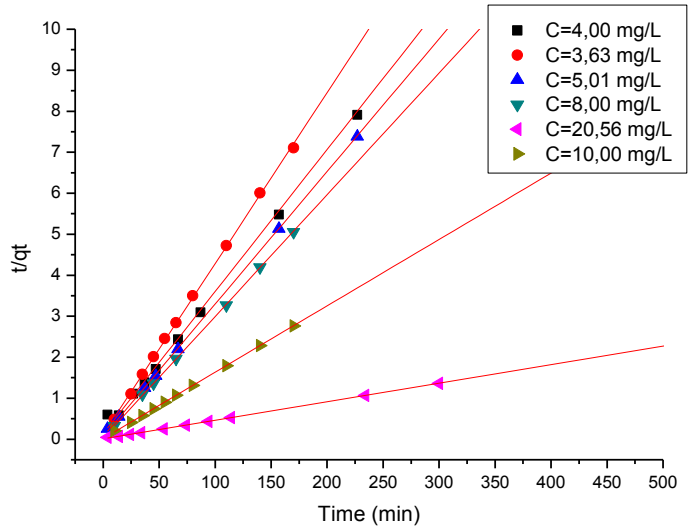

Figure.13 Pseudo-second-order kinetic for adsorption of Methylene Blue on Na-bentonite

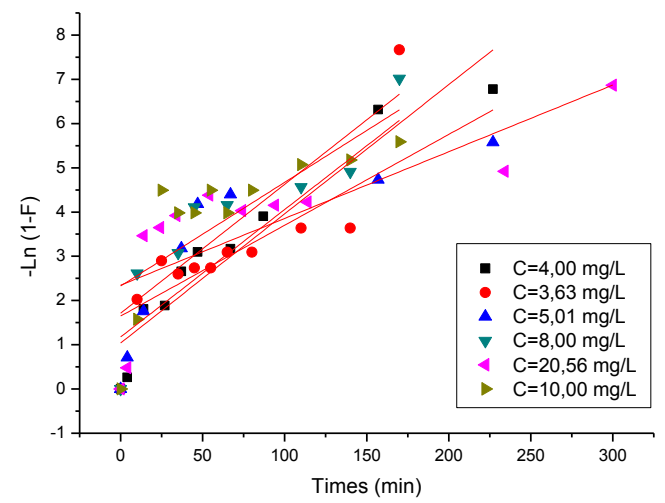

Figure.17. liquid film diffusion model kinetic for adsorption of Methylene Blue on Na-bentonite

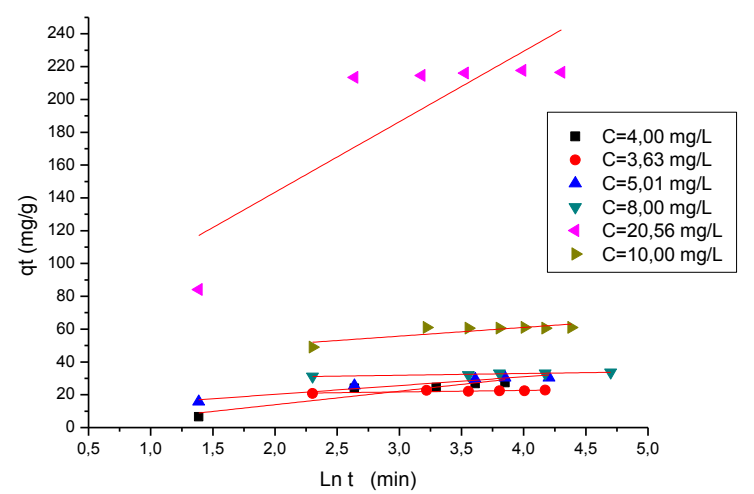

Figure.14. Elovich model kinetic for adsorption of Methylene Blue on Na-bentonite 


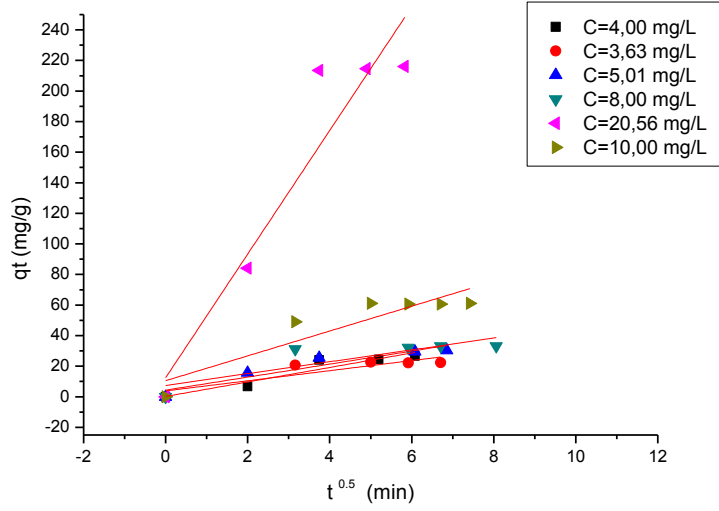

Figure.15. intra-particle I model kinetic for adsorption of Methylene Blue on Na-bentonite

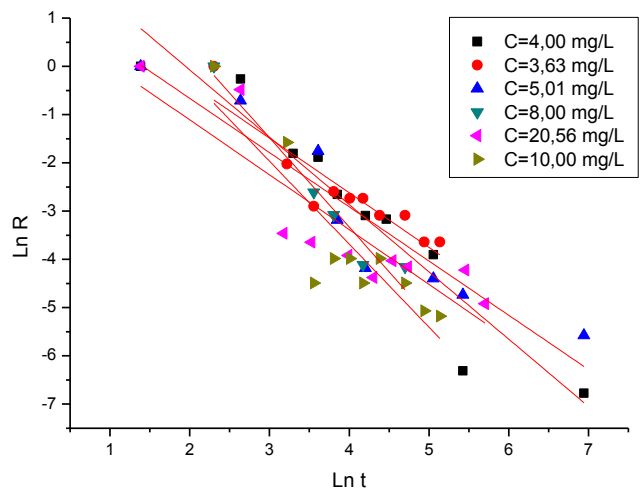

Figure.16. intra-particleII model kinetic for adsorption of Methylene Blue on Na-bentonite

\section{Conclusion}

The potential applicability of Na-bentonite clay to adsorb Methylen blue molecule from aqueous solution was investigated at various adsorbent doses. Maximum adsorption of thymol, i.e. $\geq 90 \%$ has been achieved in aqueous solutions by using $25 \mathrm{mg}$ of clay in $20 \mathrm{ml}$ of thymol solution. The maximum adsorption reached in this case is $309 \mathrm{mg}$ per gram of sodium bentonite. The Freundlich isotherms were found to be applicable for the adsorption equilibrium data of $\mathrm{MB}$ on Na-Bentonite. The adsorption kinetics of MB on NaBentonite belong to the pseudo-second order. The intraparticle diffusion plot confirmed that the sorption process was particle diffusion controlled. The regression models that were generated for these equations could be used as predictive models for MB sorption on Na-bentonite at any other contact time. The amount of MB released (desorbed) from the Na-bentonite clay was negligible in water. Mechanisms involved in the adsorption, which explain the high MB uptake and irreversibility, were the molecule fixed by the adsorbed clay on polar groups (Al-O- and Si-O-) (remaining) sites onto the basal plane and on the layer silicate edges. It is believed that due to these properties, Na-bentonite clay, shows much potential as an adsorbent for thymol.

\section{Acknowledgements}

The authors are sincerely thankful to CNRST -Morocco (PROTARS p23/66) for is financial support.

\section{Reference}

[1]. Erdal Eren, "Removal of basic dye by modified Unye bentonite, Turkey" Journal of Hazardous Materials 162 (2009) 1355-1363

[2]. Francisco G.E. Nogueira, João H. Lopes, Adilson C. Silva, Maraisa Gonçalves, Alexandre S. Anastácio, Karim Sapag, Luiz C.A. Oliveira. "Reactive adsorption of methylene blue on montmorillonite via an ESI-MS study", Applied Clay Science 43 (2009) 190195).

[3]. (Weng, Chih-Huang, Pan, Yi-Fong, 2006. Adsorption of a cationic dye "methylene blue onto spent activated clay". Journal of Hazardous Materials 144, 355-362.).

[4]. PHAM Till HANG and G. W. BRINDLEY Clays and Clay Minerals, 1970, Vol. 18, pp. 203-212. Pergamon Press. Printed in Great Britain

[5]. Fairbairn, P. E. and Robertson, R. H. S. (1957). "Liquid limit and dye adsorption: Clay Minerals Bull. 3, 129-136

[6]. (M. J. Nevins, M. J. and Weinttitt, D. J. (1967). "Determination of cation exchange capacity by methylene blue adsorption: Am. Ceram. Soc. Bull. 46, 587-592. 
[7]. Johnson, C. E. Jr. (1957). "Methylene blue adsorption and surface area measurements. Paper presented at the 131st National Meeting of the American Chemical Society, April 7-12

[8]. Worrall, W. (1958). Adsorption of basic dyestuffs by clays: Trans. Brit. Ceram, Soc. 57, 210-217

[9]. G. W. Phelps, and D. L. Harris, 1967). Specific surface and dry strength by methylene blue adsorption: Am. Ceram. Soc. Bull. 47, 1146-1150

[10]. Hul, H. J. Van Den (1966). The specific surface area of silver iodide suspensions. Thesis, Univ. Utrecht

[11]. Faruqi, F. A., Okuda, S. and Wiiliamson, W. O. (1967). Chemisorption of methylene blue by kaolinite: Clay Minerals 7, 19-31

[12]. G. Mckay, S.J. Allen, J.F. Porter, J. Colloid Interf. Sci. 280 (2004) 322-333).

[13]. (El miz Mohamed; Salhi SAMIRA; EL BACHIRI ALI; WATHELET JEAN PAUL; TAHANI ABDESSELAM. « adsorption study of thymol on na-bentonite » Journal of Environmental Solutions Volume 2 (Issue 2) (2013) 31-37).

[14]. Noll, K.E., V. Gouranis, and W.S. Hou,Adsorption Technology for Air and Water Pollution Control, Lewis Publishers, 1992.

[15]. Komiyama, H. and J.M. Smith, "Surface Diffusion in Liquid-Filled Pores,"AIChE J.,20(6), 1110-1117 (1974).

[16]. Al Duri, B., "Adsorption Modelling and Mass Transfer,"Use of Ad-sorbents for the Removal of Pollutants from Wastewaters, Ch. 7, pp. 133-173, CRC Press, 1996.

[17]. S. BAUP, C. JAFFRE, D. WOLBERT AND A. LAPLANCHE, 2000, "Adsorption of Pesticides onto Granular Activated Carbon:Determination of Surface Diffusivities Using Simple Batch Experiments", Kluwer Academic Publishers. Manufactured in The Netherlands. Adsorption 6, 219-228.

[18]. Rybicka EH, Calmano W and Breeger (1995). Heavy metals sorption/desorption on competing clay minerals: an experimental study. Applied Clay Science. 9: 369-381.

[19]. N. A. OLADOJA, C. O. ABOLUWOYE, Y. B. OLADIMEJ, 2008. "Kinetics and Isotherm Studies on Methylene Blue Adsorption onto Ground Palm Kernel Coat", Turkish J. Eng. Env. Sci. 32, $303-312$.

[20]. Gupta, V. K., Strivastava S. K. and Mohan, D., "Sorp-tion Dynamics, Process Optimization, Equilibrium Up-take and Column Operations for the Removal and Re-covery of Malachite Green Using Activated Carbon and Activated Slag" Ind. Eng. Chem. Res., $36,5545,1994$.

[21]. H. Zaitan, D. Bianchi, O. Achak, T. Chafik, (2008), "A comparative study of the adsorption and desorption of o-xylene onto bentonite clay and alumina", Journal of Hazardous Materials, Vol: 153, 852-859.

[22]. L. Amman, F. Bergaya, G. Lagaly (2005), "Determination of the cation exchange capacity (CEC) of clays with copper complexes", Revisited Clays and Clay Minerals, Vol: 40, 441-453.

[23]. F. Bergaya, M. Vayer, (1997), "CEC of Clays. Measurement by adsorption of a copper ethylene diamine complex", Applied Clay Science, Vol: 12, 275-280

[24]. Salerno P, Asenjo MB, Mendioroz S (2001). Influence of preparation method on thermal stability and acidity of Al-PILCs. Thermochimica Acta. 379: 101-109.

[25]. Puls RW, Powell RM, Clark D, and Eldred CJ (1991). Effects of pH, solid/solution ratio, ionic strength, and organic acids on Pb and Cd sorption on kaolinite. Water, Air, and Soil Pollution.

[26]. C.H. Giles, T.H. Mac Ewan, S.N. Nakhwa, D.J. Smith, Journal of Chemical Society 93 (1960) 3973.

[27]. I. Langmuir, The adsorption of gases on plane surfaces of glass, mica and plat-inum, J. Am. Chem. Soc. 40 (1918) 1361-1403.

[28]. Hall KR, Eagleton LC, Acrivos A, Vermeulen T (1966). Pore and solid diffusion kinetics in fixedbed adsorption under constant pattern conditions. I \& EC Fundam. 5: 212-223.

[29]. Treybal RE (1968). Mass Transfer Operations, 2nd edition, McGraw Hill, New York.

[30]. Ho YS, McKay G (1998). Sorption of dye from aqueous solution by peat. Chemical engineering. 70: 115-124.

[31]. Temkin MJ, Pyzhev V (1940). Recent modifications to Langmuir isotherms. Acta Physiochim., URSS, 12: 217-222.

[32]. A.R. Cestari, E.F.S. Vieira, G.S. Vieira, L.E. Almeida, J. Colloid Interf. Sci. 309 (2007) $402-411$.

[33]. S.S. Tahir, N. Rauf, Chemosphere 63 (2006) 1842-1848

[34]. Arellano-Cárdenas, S., Gallardo-Velázquez, T., Osorio-Revilla,G., López-Cortéz, M. and Gómez-Perea, B. (2005). Adsorption of Phenol and Dichlorophenols from Aqueous Solutions by Porous Clay Heterostructure (PCH). J. Mex. Chem. Soc., 49 (3), $287-291$.

[35]. Hamdaoui O, Chiha M (2007). Removal of Methylene Blue from Aqueous Solutions by Wheat Bran. Acta Chim. Slov. 54, $407-418$.

[36]. Zohre Shahryari, Ataallah Soltani Goharrizi* and Mehdi Azadi, "Experimental study of methylene blue adsorption from aqueous solutions onto carbon nano tubes", International Journal of Water Resources and Environmental Engineering Vol.2 (2), pp. 016028, March, 2010 .

[37]. Ho,Y.S. and Ofomaja, A.E., "Kinetics and Thermody-namics of Lead Ion Sorption On Palm Kernel Fiber From Aqueous Solution" Process biochemistry, 40,3455-3461, 2005a

[38]. Chien, S.H. and Clayton W.R., "Applications of Elovich Equation to the Kinetics of Phosphate Release and Sorption in Soils" Soil Sci. Soc. Am. J., 44, 265, 1980.

[39]. Weber, W.J. and Morris, J.C., "Kinetics of Adsorption on Carbon from Solution", J. Sanit. Eng. Div. ASCE 89, 31, 1963.

[40]. Boyd, G.E., Adamson, A.W. and Myers, Jr., L.S., "The Exchange Adsorption of Ions from Aqeous Solutions by Organic Zeolites" (II) Kinetics. Journal of American Chemical Society., 69,2836-2848, 1947.

[41]. Abechi E.S, Gimba C.E, Uzairu A, Kagbu J.A, 2011. "Kinetics of adsorption of methylene blue onto activated carbon prepared from palm kernel shell”, Arch. Appl. Sci. Res., 2011, 3 (1):154-164

[42]. Demirbas, E. Kobya, M, Senturk, E. Ozkan, T. (2004). Water SA30 (4), pp 533 -539.

[43]. G"unay A, Arslankaya E, Tosun I (2007). Lead removal from aqueous solution by natural and pretreated clinoptilolite: Adsorption equilibrium and kinetics. J. Hazard. Mater. 146: 362-371.

[44]. Goswami, S. and Ghosh, U.C., "Studies on Adsorption Behaviour of Cr (VI) Onto Synthetic Hydrous Stannic Oxide" Water SA 31, 44, 57-602, 2005

[45]. Srivastava SK, Tyagi R, Pant N (1989). Adsorption of heavy metal ions on Carbonaceous material developed from the waste slurry generated in local fertilizer plants. Water Reserch. 23: 1161-1165.

[46]. Igwe JC, and Abia AA (2007). Adsorption kinetics and intra-particulate diffusivities for bioremediation of Co (II), Fe (II) and Cu (II) ions from waste water using modified and unmodified maize cob. International Journal of Physical Sciences. 2 (5): $119-127$.

[47]. Hameed, B.H., Din, A.T.M., Ahmad, A.L.,(2006). J. Hazard Mater.July 28, 16956720.

[48]. Demirbas, E. Kobya, M, Senturk, E. Ozkan, T. (2004). Water SA30 (4), pp 533 -539.

[49]. O"zer A, Dursun G (2007). Removal of methylene blue from aqueous solution by dehydrated wheat bran carbon. J. Hazard. Mater.146: 262-269.

[50]. Wang L, Zhang J, Wang A (2008b). Removal of methylene blue from aqueous solution using chitosan-g-poly (acrylic acid)/montmorillonite superadsorbent nanocomposite. Colloids and Surfaces A: Physicochem. Eng. Aspects 322: 47-53. 
Adsorption-desorption and kinetics studies of Methylene Blue Dye on Na-bentonite from Aqueous

[51]. Dermirbas E, Kobya M, Senturk E, Ozkan T (2004). Adsorption Kinetics for the removal of Chromium (VI) from aqueous solutions on the activated carbons prepared from agricultural wastes. Water SA. 30(4): 533-539. 